\title{
Novel combination treatment of type 2 diabetes DPP-4 inhibition + metformin
}

\author{
Bo Ahrén \\ Department of Clinical Sciences, \\ Division of Medicine, Lund University, \\ Lund, Sweden
}

\begin{abstract}
Inhibition of dipeptidyl peptidase-4 (DPP-4) as a novel therapy for type 2 diabetes is based on prevention of the inactivation process of bioactive peptides, the most important in the context of treatment of diabetes of which is glucagon-like peptide-1 (GLP-1). Most clinical experience with DPP-4 inhibition is based on vildagliptin (Galvus ${ }^{\mathrm{R}}$, Novartis) and sitagliptin (Januvia ${ }^{\mathrm{R}}$, Merck). These compounds improve glycemic control both in monotherapy and in combination with other oral hyperglycemic agents. Both have also been shown to efficiently improve glycemic control when added to ongoing metformin therapy in patients with inadequate glycemic control. Under that condition, they reduce $\mathrm{HbA}_{1 \mathrm{c}}$ levels by $0.65 \%-1.1 \%$ (baseline $\mathrm{HbA}_{1 \mathrm{c}} 7.2-8.7 \%$ ) in studies up to 52 weeks of duration in combination versus continuous therapy with metformin alone. Sitagliptin has also been examined in initial combination therapy with metformin have; $\mathrm{HbA}_{1 \mathrm{c}}$ was reduced by this combination by $2.1 \%$ (baseline $\mathrm{HbA}_{1 \mathrm{c}} 8.8 \%$ ) after 24 weeks of treatment. Both fasting and prandial glucose are reduced by DPP-4 inhibition in combination with metformin in association with improvement of insulin secretion and insulin resistance and increase in concentrations of active GLP-1. The combination of DPP-4 inhibition and metformin has been shown to be highly tolerable with very low risk of hypoglycemia. Hence, DPP-4 inhibition in combination with metformin is an efficient, safe and tolerable combination therapy for type 2 diabetes.
\end{abstract}

Keywords: DPP-4 inhibition, sitagliptin, vildagliptin, metformin, type 2 diabetes

\section{Introduction}

It is known that both the level and the duration of hyperglycemia in type 2 diabetes are closely related to the risk of developing diabetic complications (Stratton et al 2000). Therefore, achieving glycemic control is a prerequisite for prevention of cardiovascular and microvascular complications in type 2 diabetes. Lifestyle interventions, including dietary adjustments and increased physical activity, are cornerstones of the therapy. For most patients, however, pharmacological intervention is required and present guidelines suggest metformin to be a first line treatment (Inzucchi 2000; Nathan et al 2006). Metformin is an inexpensive compound with documented glucose-lowering effect in both obese and non-obese subjects with type 2 diabetes (Inzucchi 2002; Hundal and Inzucchi 2003; Setter et al 2003; Consoli et al 2004; Donnelly et al 2006). Metformin reduces glycemic levels primarily by inhibiting hepatic glucose output (Bailey and Turner 1996; Leverve et al 2003; Stumvoll et al 1995). Metformin has also been shown to improve insulin sensitivity in liver and muscle (Ginnarelli et al 2003). Additional suggested mechanistic effects of metformin are inhibition of glucose absorption in the gut (Ikeda et al 2000) and increase in plasma levels of GLP-1 (Mannucci et al 2001). As has been reviewed (Bailey and Turner 1996), metformin reduces $\mathrm{HbA}_{1 \mathrm{c}}$ levels in the range of $1 \%-1.5 \%$, depending on the baseline $\mathrm{HbA}_{1 \mathrm{c}}$ levels and the compound is well tolerated, although gastrointestinal adverse events are quite common during the initiation of the therapy. Hypoglycemia is rarely seen during metformin therapy, and the 
potential fatal adverse event of lactic acidosis is uncommon; nevertheless cautious should always be exercised when treating subjects with renal insufficiency with metformin.

\section{Add-on treatment to metformin often required}

In spite of the beneficial effects of metformin in improving glycemic control, very often, however, metformin alone is insufficient for achievement of good metabolic control. Often, also, glycemic control deteriorates in metformintreated patients. This necessitates combination therapy by adding a secondary compound to metformin. Most often, sulphonylureas are added (Inzucchi 2002; Nathan et al 2006). The rationale for this combination is that sulphonylureas stimulate insulin secretion, which is a complimentary mechanism to the improvement in insulin sensitivity by metformin. Other combinations with metformin include thiazolidinediones and insulin (Hundal and Inzucchi 2003; Setter et al 2003; Charbonnel et al 2005; Derosa et al 2006; Umpierrez et al 2006). However, the combinations with sulphonylureas and thiazolidinediones have faced problems, in that sulphonylureas increase the risk of hypoglycemia (Del Prato and Pulizzi 2006; Green and Feinglos 2007) and thiazolidinediones result in weight gain and potential problems of cardiovascular adverse events and increase in the risk of bone fractures in women (Kahn et al 2006; Levetran 2007; Nissen and Wolski 2007). Also the novel GLP-1 based therapy has been found to be successful in combination with metformin. This applies both to the strategy of activating the GLP-1 receptors by exenatide (DeFronzo et al 2005) or liraglutide (Feinglos et al 2005), and by the strategy of preventing the inactivation of endogenous GLP-1 by inhibiting dipeptidyl peptidase-4 (DPP-4) (Ahrén et al 2004; Charbonnel et al 2006; Bosi et al 2007; Brazg et al 2007; Goldstein et al 2007). This review summarizes the experience of combining metformin and a DPP-4 inhibitor in the treatment.

\section{GLP-I as a target for treatment of type 2 diabetes}

The rationale for the development of DPP-4 inhibition in the treatment of type 2 diabetes relies on augmentation of the incretin effect (Holst and Deacon 1998). The incretin effect is the exaggerated insulin secretion that follows oral glucose administration when compared to intravenous glucose administration and it is attributed to gut hormones augmenting glucose-stimulated insulin secretion (Drucker and Nauck 2006). The two most important incretin hormones are glucose-dependent insulinotropic polypeptide (GIP) and glucagon-like peptide-1 (GLP-1) (Drucker and Nauck 2006). GLP-1 is produced in L-cells, which are located mainly in the distal portion of the ileum. GLP-1 is released during meal ingestion and stimulates insulin secretion in a glucosedependent manner (Drucker and Nauck 2006). GLP-1 also inhibits glucagon secretion (Dunning et al 2005), delays gastric emptying (Nauck et al 1997) and induces satiety (Gutzwiller et al 1999). In addition, animal studies have presented evidence that GLP-1 increases beta cell mass by stimulating proliferation and inhibiting apoptosis (Perfetti and Hui 2004), although it should be emphasized that such an effect has not been demonstrated in humans. Because all these effects would be important in the treatment of type 2 diabetes, GLP-1 has been developed as a novel therapy (Ahrén and Schmitz 2004). The development of GLP-1 as a therapy has, however, been complicated by its rapid inactivation, which is due to removal of the N-terminal dipeptide end through DPP-4, which inactivates GLP-1 (Mentlein 1999). To overcome this, two strategies have been used. One strategy is the development of GLP-1 receptor agonists (GLP-1 mimetics such as exenatide and liraglutide), which are resistant to DPP-4 (Ahrén and Schmitz 2004). The other strategy is the development of inhibitors of DPP-4, which prevent the inactivation of GLP-1 and thereby enhance and prolong the action of the endogenous incretin hormone (Ahrén and Schmitz 2004; Mari et al 2005; Ahrén 2007a, 2007b). DPP-4 inhibition also prevents the inactivation of the other incretin hormone, GIP, and therefore the concentrations of the active form also of this hormone are increased during DPP-4 inhibition (Mari et al 2005). However, since the action of GIP to stimulate insulin secretion is almost entirely lost in type 2 diabetes (Vilsbøll et al 2002), this raise of GIP concentrations is of less importance.

\section{DPP-4 inhibition as a target for treatment of type 2 diabetes}

The rational of DPP-4 inhibition for the treatment of type 2 diabetes was outlined already in 1998 (Holst and Deacon 1998). The first proof-of-concept study of DPP-4 inhibition showed improved metabolic control with reduced fasting and prandial glucose levels and reduction of $\mathrm{HbA}_{1 \mathrm{c}}$ after 4 weeks of treatment of the DPP-4 inhibitor, NVP-DPP728 (Ahrén et al 2002). Improved glycemic control by DPP-4 inhibition has been confirmed in many studies with other compounds and today several DPP-4 inhibitors are in the progress of development (Ahrén 2007a, 2007b). Most experience exists for vildagliptin (LAF237, Galvus ${ }^{\mathrm{R}}$, Novartis) and sitagliptin (MK-0431, Januvia ${ }^{\mathrm{R}}$, Merck), which are orally active 
compounds, which efficiently inhibit DPP-4 activity (Ahrén 2006; Kim et al 2005). Both compounds inhibit plasma DPP-4 activity for more than 16 hours after a single administration and are therefore both possible to administer once daily. Furthermore, they have both been shown to improve glycemic control when used in monotherapy as well as in combination therapy with metformin and thiazodilidinedione (Ahrén 2006; Deacon 2007; Gallwitz 2007). Sitagliptin has been approved for treatment of type 2 diabetes in the US and in Europe in combination with metformin and vildagliptin has been approved for treatment of type 2 diabetes in Europe. Of particular importance is that DPP-4 inhibitors are safe and tolerable and that this in combination with their efficiency allow them to be used in early stages of the disease. One such early indication would be to use DPP-4 inhibitors in combination with metformin.

\section{Rationale for combining metformin with DPP-4 inhibition}

Type 2 diabetes develops when insulin secretion is insufficiently raised to match insulin resistance (Kahn 2001; DeFronzo 2004). In addition, glucagon levels are inappropriately elevated, which enhances hepatic glucose output and increases fasting glucose (Dunning et al 2005). Therefore, diabetes is a disease with at least three main defects, which need to be corrected: impaired insulin secretion, insulin resistance and hypersecretion of glucagon. The rationale for combining metformin with DPP-4 inhibitors is the complimentary mechanism of action of the two strategies. Thus, metformin acts primarily by reducing hepatic glucose output and improving insulin sensitivity in liver and muscle (Stumvoll et al 1995; Bailey and Turner 1996; Hundal and Inzucchi 2003; Leverve et al 2003; Setter 2003) whereas DPP-4 inhibitors act by increasing GLP-1 levels and thereby stimulating insulin secretion and inhibiting glucagon secretion (Ahrén 2007a; Ahrén 2007b). The two strategies therefore have the potential to improve different mechanisms, which are defective in type 2 diabetes and therefore an additive or synergistic action when used in combination is anticipated. In addition, metformin has been shown to increase GLP-1 levels (Mannucci et al 2001), which would be a potential for an additional synergistic action with DPP-4 inhibitors. The mechanism underlying the increase in GLP-1 levels by metformin remains to be finally established; it has been suggested to be caused by inhibition of DPP-4 (Lindsay et al 2005; Mannucci et al 2001), although there are also findings that metformin does not affect DPP-4 activity (Hinke et al 2002). Instead, more recent findings suggest that metformin stimulates the secretion of GLP-1 from the gut (Migoya et al 2007). Hence, from a mechanistic point of view, there is a clear rationale for combining metformin with DPP-4 inhibitors. Another important information is that the pharmacokinetics of metformin and a DPP-4 inhibitor do not change by combining the two, as shown for sitagliptin, which further indicates the feasibility of the combination (Herman et al 2006).

\section{Vildagliptin and sitagliptin as monotherapy}

Both vildagliptin and sitagliptin reduce fasting and prandial glucose as well as $\mathrm{HbA}_{1 \mathrm{c}}$ when used in monotherapy for the treatment of type 2 diabetes; $\mathrm{HbA}_{1 \mathrm{c}}$ has been shown to be reduced by these compounds by $0.65 \%-1.1 \%$ after study periods of 3-12 months from baseline levels of 7.2\%-8.7\% (Ahrén et al 2004b; Ristic et al 2005; Aschner et al 2006; Pratley et al 2006; Raz et al 2006; Rosenstock et al 2007; Schweizer et al 2007; Scott et al 2007). Furthermore, these studies have shown that both vildagliptin and sitagliptin are safe and tolerable with incidences of adverse events not different from what is seen after placebo treatment and that there is a very low rate of hypoglycemia during the treatment with the DPP-4 inhibitors. Recent reviews have summarized these monotherapy studies in more detail (Ahrén 2007a, 2007b).

\section{DPP-4 inhibition as add-on therapy to metformin}

Several studies have reported the experience of treatment with a DPP-4 inhibitor in combination with metformin. The first combination study was a 52 week trial, in which vildagliptin at $50 \mathrm{mg}$ daily or placebo was added to ongoing treatment with metformin (1.5-3 g daily) in patients with a mean baseline $\mathrm{HbA}_{1 \mathrm{c}}$ of $7.8 \%$ (Ahrén et al 2004a). The patients had a mean diabetes duration of 5.5 years and they had been on metformin treatment for 29 months as a mean. The results are illustrated in Figure 1 and show that following the initial 12 week study period, $\mathrm{HbA}_{1 \mathrm{c}}$ was reduced by $0.7 \%$ by vildagliptin in combination with metformin compared to metformin alone. After the first 12 weeks of study, patients were followed for another 40 weeks. During this period, $\mathrm{HbA}_{1 \mathrm{c}}$ increased by $0.066 \% /$ month in patients given metformin alone versus only by $0.013 \% /$ month after vildagliptin plus metformin. The between-group difference in change of $\mathrm{HbA}_{1 \mathrm{c}}$ after 52 week of treatment was $1.1 \%$, showing a clinically important improvement of the glycemic control by adding vildagliptin to metformin. Furthermore, fasting glucose was also reduced by vildagliptin in combination with metformin compared to 


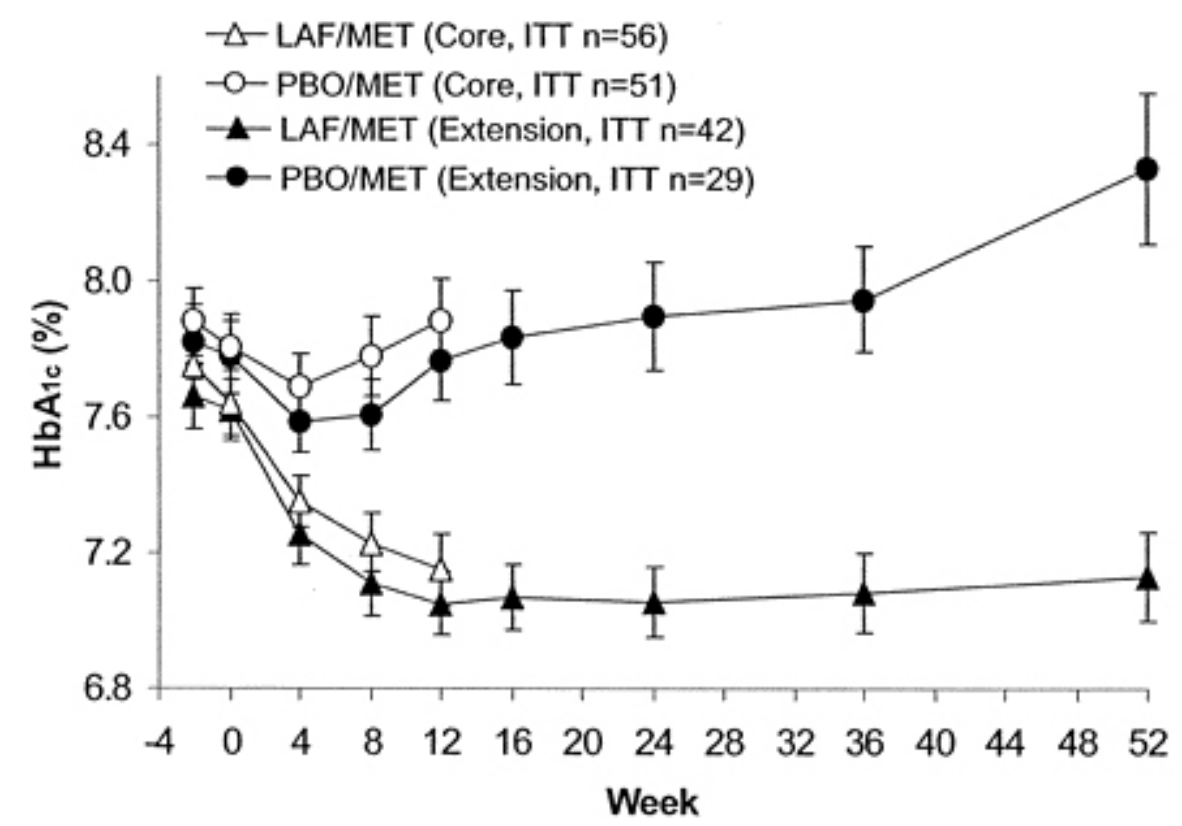

Figure I Time course of $\mathrm{HbA}_{\mathrm{lc}}$ in a 12 week core study and a 40 week extension study when vildagliptin (LAF; 50 mg once daily) was given as add-on to metformin (MET). $\mathrm{PBO}=$ placebo. Reproduced from Ahrén et al 2004a after permission from the American Diabetes Association.

metformin alone. Thus, from a mean baseline fasting glucose of $9.8 \mathrm{mmol} / \mathrm{l}$ across all patients, the between-group difference in fasting glucose after 52 weeks of treatment was $1.1 \mathrm{mmol} / \mathrm{l}$. The study therefore suggests that addition of vildagliptin to metformin prevents the deterioration of glycemic control seen in these patients when given metformin alone. The study also shows that the combination of vildagliptin and metformin is safe and highly tolerable with an overall incidence of any adverse event being similar in the two groups.

A second study in 416 patients added vildagliptin at 50 $\mathrm{mg}$ once or twice daily to on-going treatment with metformin for a study period of 24 weeks (Bosi et al 2007). The patients in this study had a mean diabetes duration of 6 years and had been treated with metformin for a mean of 16 months, their mean daily metformin dose was $2.1 \mathrm{~g}$ (inclusion criteria $>1.5 \mathrm{~g}$ daily). They had a mean baseline $\mathrm{HbA}_{1 \mathrm{c}}$ was $8.4 \%$. Figure 2 shows the $\mathrm{HbA}_{1 \mathrm{c}}$ levels in this study. It is seen that $\mathrm{HbA}_{1 \mathrm{c}}$ was reduced by $0.5 \%$ in patients given vildagliptin at $50 \mathrm{mg}$ daily and $0.9 \%$ in patients given vildagliptin at $100 \mathrm{mg}$ daily, both in combination with metformin, versus an increase by $0.2 \%$ in patients given placebo with on-going metformin. The placebo-adjusted mean reduction in $\mathrm{HbA}_{1 \mathrm{c}}$ was therefore $0.7 \%$ by vildagliptin at $50 \mathrm{mg}$ and $1.1 \%$ by vildagliptin at $100 \mathrm{mg}$ daily. The data were also analysed with respect to how many patients who experienced improved glycemic control or had a deterioration of glycemic control. The analysis revealed that in the group given metformin alone, $35 \%$ of patients had a deterioration of glycemic control and 31\% had no meaningful change in glycemic control. In contrast, of the patients given vildagliptin at $50 \mathrm{mg}$ in combination with metformin, 38\% showed a meaningful improvement in glycemic control and 29\% had a marked improvement in glycemic control (defined as reduction in $\mathrm{HbA}_{1 \mathrm{c}}$ by more than $1 \%)$. Also fasting plasma glucose was reduced by vildagliptin in combination with metformin. Baseline fasting glucose was $9.7 \mathrm{mmol} / \mathrm{l}$ across all groups. In the group given metformin alone, fasting glucose increased by $0.7 \mathrm{mmol} / 1$ and the placebo-adjusted reduction in fasting glucose was $0.8 \mathrm{mmol} / 1$ in subjects given vildagliptin at $50 \mathrm{mg}$ daily and $1.7 \mathrm{mmol} / 1$ in subjects given vildagliptin at $100 \mathrm{mg}$ in combination with metformin. Except for fasting triglycerides, lipid values were not significantly altered in any of the groups. However, fasting triglycerides increased from a mean value of $2.3 \mathrm{mmol} / \mathrm{l}$ by $19 \%$ in subjects given metformin alone but only by $1 \%$ in subjects given vildagliptin at $50 \mathrm{mg}$ in combination with metformin and by $5 \%$ in the group given vildagliptin at $100 \mathrm{mg}$ in combination with metformin. Mean body weight was $94 \mathrm{~kg}$ as a mean across all study groups and did not change significantly in the subjects given vildagliptin at either 50 or $100 \mathrm{mg}$ daily in combination with metformin, whereas body weight was reduced by $1.0 \mathrm{~kg}$ in subjects given metformin alone. Finally, total number of adverse events was not significantly different between the groups; the only difference was a reduction in gastrointestinal adverse events in the subjects given vildagliptin at $50 \mathrm{mg}$ in combination with metformin $(9.6 \%)$ versus in those given metformin alone (18.2\%). In 


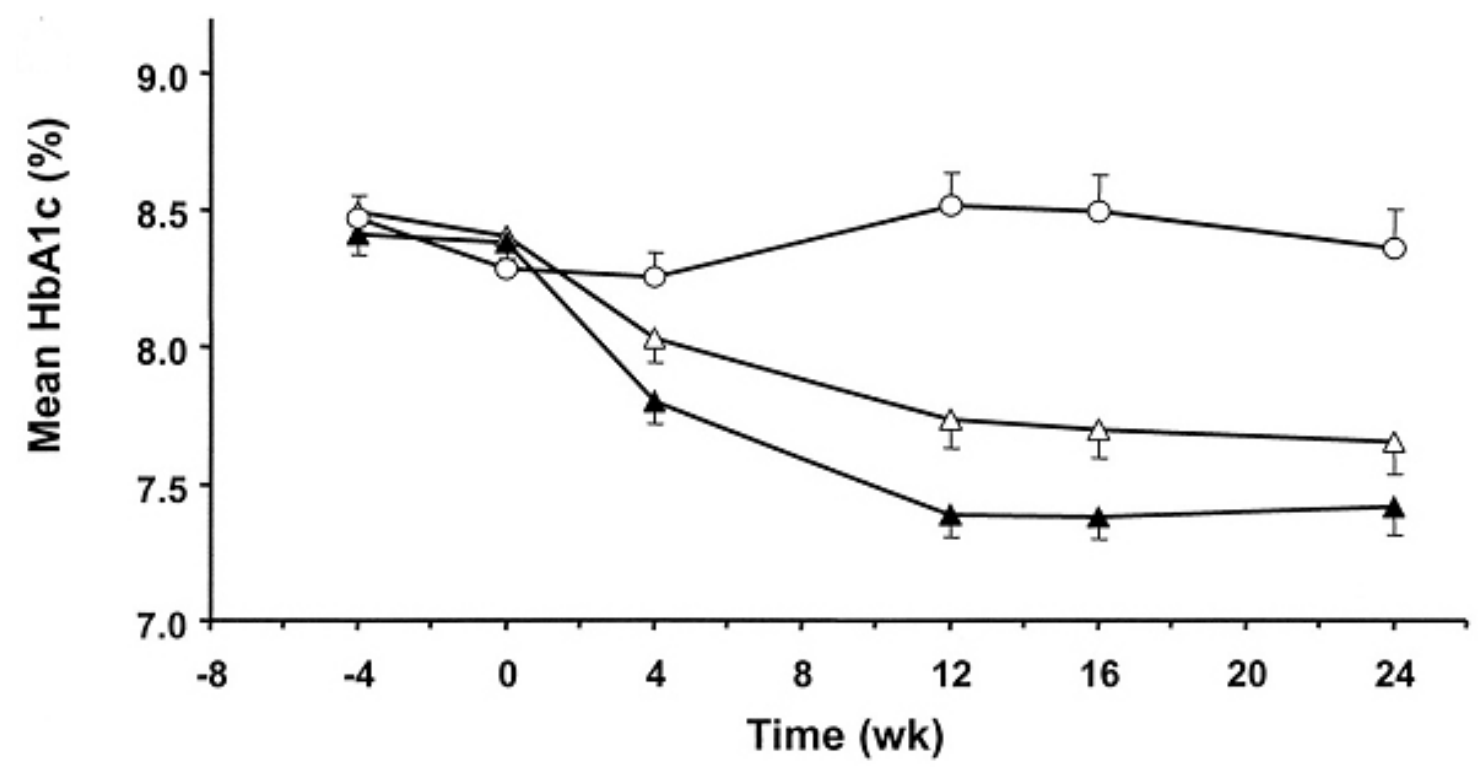

Figure 2 Time course of mean $\mathrm{HbA}_{\mathrm{Ic}}$ levels during 24 week treatment with vildagliptin at $50 \mathrm{mg}$ daily $(\Delta)$ or $100 \mathrm{mg}$ daily $(\mathbf{\Delta})$ or placebo $(\mathrm{O})$ in patients with type 2 diabetes continuing stable metformin treatment ( $\geq 1.5 \mathrm{~g}$ daily). Reproduced from Bosi et al 2007 after permission from the American Diabetes Association.

conclusion, this large study showed that vildagliptin is well tolerated when given as add-on to metformin for a study period of 24 weeks and that vildagliptin shows a clinically meaningful improvement in glycemic control as verified by dose-related reductions in $\mathrm{HbA}_{1 \mathrm{c}}$ and fasting glucose.

The first study on the effect of sitagliptin as add-on therapy to patients with inadequate glycaemic control on metformin monotherapy was a four week study in 28 patients (Brazg et al 2007). The patients had a mean duration of diabetes of 6.6 years, the mean baseline $\mathrm{HbA}_{1 \mathrm{c}}$ was $7.7 \%$ and the mean fasting plasma glucose was $8.4 \mathrm{mmol} / \mathrm{l}$. The study showed that fasting glucose was reduced by $1.3 \mathrm{mmo} / \mathrm{l}$ by sitagliptin in combination with metformin versus only by $0.4 \mathrm{mmol} / \mathrm{l}$ by metformin alone. The study also included a $24 \mathrm{hr}$ measurement of glucose after the four week treatment period, and this showed a reduction of glucose by approximately $1-1.5 \mathrm{mmol} / \mathrm{l}$ throughout the entire $24 \mathrm{~h}$ period. Both fasting and prandial glycemia were reduced by this degree. Furthermore, the number of adverse events was not different when sitagliptin was given in combination with metformin versus when metformin was given alone. Hence, this shortterm study verified the efficient improvement in glycemic control by the addition of DPP-4 inhibition to on-going metformin therapy in association with safety and tolerability of the combination therapy.

In a long-term study on the effect of sitagliptin as add-on to metformin in subjects with inadequate glycemic control, sitagliptin (100 mg once daily) was added to metformin ( $>1.5 \mathrm{~g}$ daily) for 24 weeks (Charbonnel et al 2006). The study comprised a total of 701 patients who had a mean diabetes duration of 6.2 years, a mean baseline $\mathrm{HbA}_{1 \mathrm{c}}$ of $8.0 \%$ and a mean baseline fasting glucose of $9.5 \mathrm{mmol} / \mathrm{l}$. Figure 3 shows the $\mathrm{HbA}_{1 \mathrm{c}}$ in this study. It is seen that addition of sitagliptin significantly reduced the $\mathrm{HbA}_{1 \mathrm{c}}$ levels after the 24 week treatment period. The placebo-subtracted reduction in $\mathrm{HbA}_{1 \mathrm{c}}$ by sitagliptin was $0.65 \%$. A total of $47 \%$ of the patients treated with sitagliptin in combination with metformin reached the target of $<7 \%$ in $\mathrm{HbA}_{1 \mathrm{c}}$ while the target was reached by only $18 \%$ of the subjects given metformin alone. Also fasting glucose was reduced by sitagliptin in combination with metformin versus metformin alone; the placebo-subtracted reduction by sitagliptin was $1.4 \mathrm{mmol} / \mathrm{l}$. The study also showed that sitagliptin in combination with metformin slightly, although significantly, reduced total cholesterol and triglycerides, whereas HDL-cholesterol was slightly increased. Body weight was slightly reduced in both groups, with no difference between the groups, and, similarly, the degree of adverse events did not differ between the groups. Hence, this 24 week trial in a large number of patients showed that sitagliptin when added to on-going therapy with metformin efficiently reduces $\mathrm{HbA}_{1 \mathrm{c}}$ and fasting glucose in combination of being a safe and highly tolerable combination therapy. Following the end of the 24 week trial, patients who did not receive glycemic rescue medication continued to an extension study. During this extension, 387 patients continued with the combination of sitagliptin with metformin throughout a 54 week study period. It was found that the mean $\mathrm{HbA}_{1 \mathrm{c}}$ remained stable at $7.1 \%$ during 


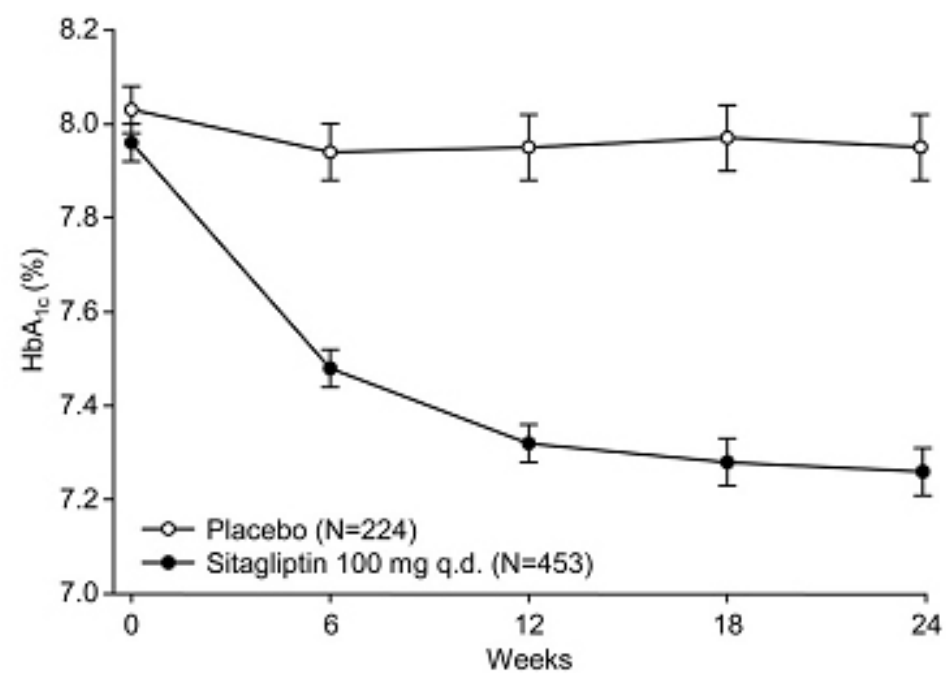

Figure 3 Time course of mean $\mathrm{HbA}^{\mathrm{lc}}$ levels during 24 week treatment with sitagliptin ( $100 \mathrm{mg}$ once daily; $\bullet$ ) or placebo (O) in patients with type 2 diabetes with on-going treatment with metformin ( $\geq 1.5 \mathrm{~g}$ daily). Reproduced from Charbonnel et al 2006 after permission from the American Diabetes Association.

this entire period and, furthermore, the combination was well tolerated during the period (Karasik et al 2007). Hence, combination of sitagliptin and metformin produced a durable reduction in $\mathrm{HbA}_{1 \mathrm{c}}$.

Another study with sitagliptin the addition of the compound (100 mg once daily) with that of glipizide (dosetitration to a maximal doe of $20 \mathrm{mg}$ daily) to the on-going treatment with metformin ( $>1.5$ g daily) in a 52 week study comprising a total of 1,172 patients (Nauck et al 2007). The mean baseline $\mathrm{HbA}_{1 \mathrm{c}}$ levels was $7.5 \%$ and this was reduced by $0.67 \%$ both by sitagliptin and by glipizide. The occurrence of hypoglycemia was higher in the group given glipizide (32\% of patients exhibited one episode of hypoglycemia) than in the group receiving sitagliptin (5\%). Furthermore, the mean body weight increased by $1.1 \mathrm{~kg}$ in the group given glimepiride versus a reduction by $1.5 \mathrm{~kg}$ in the group given sitagliptin. Hence, also this study showed a good improvement in glycemic control by the combination of a DPP-4 inhibitor with metformin.

Recently, it was also reported that the DPP-4 inhibitor, saxagliptin (Bristol-Myers-Squibb), improved glycemic control when added to metformin (DeFronzo et al 2007). The study comprised a total of 743 patients with a mean $\mathrm{HbA}_{1 \mathrm{c}}$ of $8.0 \%$ and a mean fasting glucose of $9.8 \mathrm{mmol} / 1$ when treated with metformin alone. Saxagliptin was added at $2.5,5$ or $10 \mathrm{mg}$ daily and the study also included a placebo arm; all patients continued with metformin. It was found that after 24 weeks of treatment, saxagliptin had reduced $\mathrm{HbA}_{1 \mathrm{c}}$ by 0.7 or $0.8 \%$ when adjusted for placebo in the three arms. Fasting glucose was reduced by $0.9-1.1 \mathrm{mmol} / 1$.
As for the other DPP-4 inhibitors, also saxagliptin was safe and tolerable and body weight neutral when added to metformin.

The studies thus presented sofar with DPP-4 inhibitors as add-on therapy to metformin show clinically important improvement in glycemic control. Mean $\mathrm{HbA}_{1 \mathrm{c}}$ levels are reduced by approximately $0.65 \%-1 \%$ from a baseline of $7.8 \%-8.4 \%$. Furthermore, the combination is tolerable and safe with similar adverse events profile as placebo-treated patients given metformin alone.

\section{DPP-4 inhibition and metformin as initial combination therapy}

During recent years there has been a discussion of introducing initial combination therapy when pharmacological treatment is required for type 2 diabetes, in order to reach therapeutic goal at an earlier stage and to avoid or delay subsequent changes in therapy for the maintenance of therapeutic goal. One study has examined the possibility of combining DPP-4 inhibition with metformin as initial combination (Goldstein et al 2007). The study was a 24 -week randomized trial comprising 1,092 patients with type 2 diabetes having a mean baseline $\mathrm{HbA}_{1 \mathrm{c}}$ value of $8.7 \%$ and a mean baseline fasting glucose of $11 \mathrm{mmol} / \mathrm{l}$. The patients were assigned to one of six treatment arms with sitagliptin $50 \mathrm{mg}+$ metformin $500 \mathrm{mg}$ twice daily, sitagliptin $50 \mathrm{mg}+$ metformin $1000 \mathrm{mg}$ twice daily, metformin alone at 500 or 1000 twice daily, sitagliptin alone at $100 \mathrm{mg}$ once daily or placebo. The results showed that in all treatment groups, except the placebo group, 
a significant reduction in $\mathrm{HbA}_{1 \mathrm{c}}$ after the 24 week trial period occurred. The placebo-controlled reduction of $\mathrm{HbA}_{1 \mathrm{c}}$ was in the range of $0.8 \%-2.1 \%$ in the different groups (Figure 4 ), and when comparing monotherapy versus the initial combination therapy, it was found that combination therapy produced additive effects of improved glycemic control. Hence, the largest reduction in $\mathrm{HbA}_{1 \mathrm{c}}(2.1 \%)$ was seen in the group given sitagliptin $50 \mathrm{mg}+$ metformin $1000 \mathrm{mg}$ twice daily. Similarly, fasting glucose was additively reduced by the combination therapy, and the placebo-adjusted reduction in fasting glucose in the group given sitagliptin $50 \mathrm{mg}+$ metformin $1000 \mathrm{mg}$ twice daily was $3.8 \mathrm{mmol} / \mathrm{l}$. The percentage of subjects in each group who reached the treatment target of $\mathrm{HbA}_{1 \mathrm{c}}<7.0 \%$ was $66 \%$ in the group given sitagliptin
$50 \mathrm{mg}+$ metformin $1000 \mathrm{mg}$ twice daily versus only $38 \%$ in the group given metformin at $1000 \mathrm{mg}$ twice daily alone or $20 \%$ in the group given sitagliptin at $100 \mathrm{mg}$ daily alone and only $9 \%$ in the placebo group. Hence, the initial combination of sitagliptin and metformin efficiently improved glycemic control over a 24 week study period. The number of adverse events was low and the incidences of gastrointestinal adverse events were similar when sitagliptin was added to metformin as when metformin was given alone. Furthermore, the incidence of hypoglycemia was low $(0.5 \%-2.2 \%$ in the different actively treated groups) and not significantly different from the placebo group (0.6\%). Finally, in regard to body weight, there was a significant reduction in body weight after 24 weeks of treatment in all actively treated groups
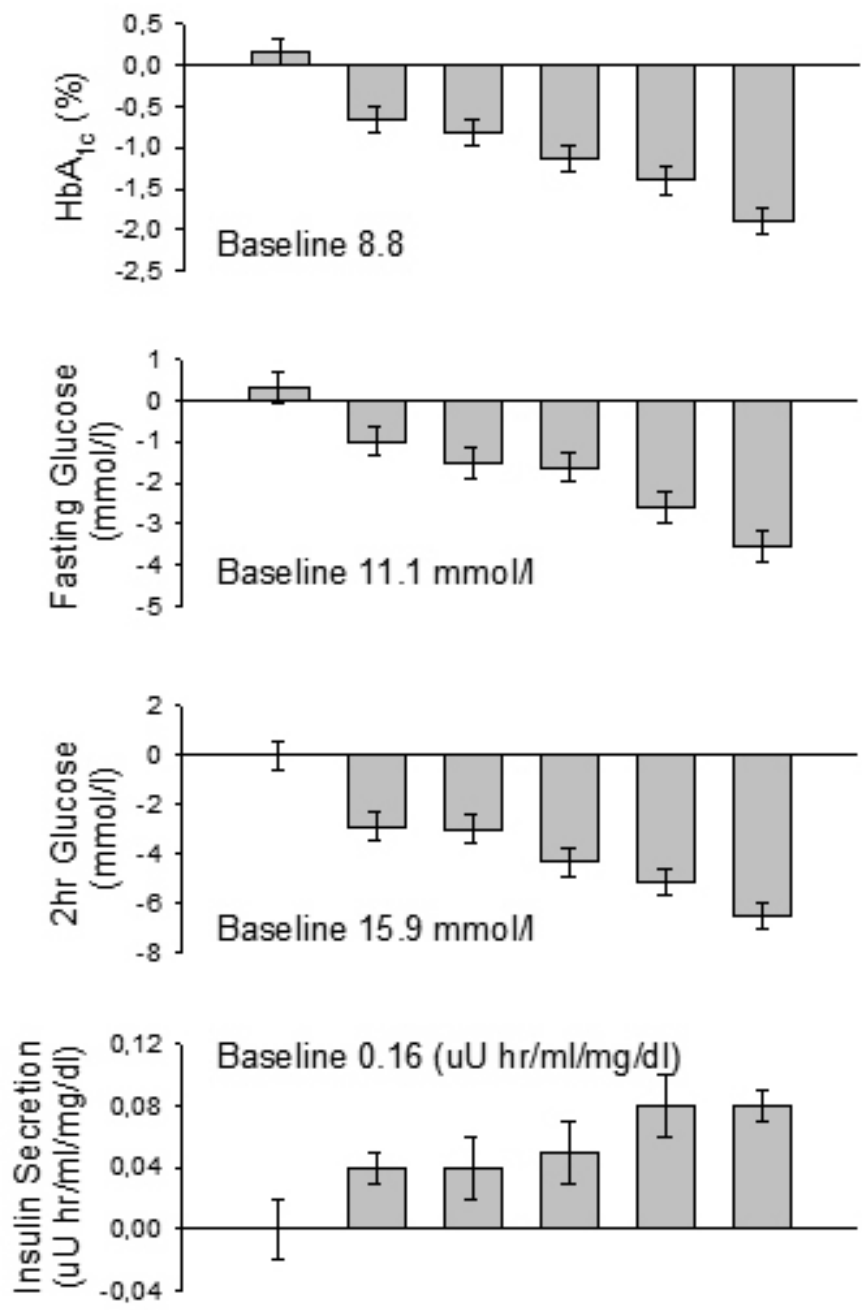

$\begin{array}{lrrcccc}\text { Sitagliptin } & 0 & 100 & 0 & 0 & 100 & 100 \mathrm{mg} \text { daily } \\ \text { Metformin } & 0 & 0 & 1000 & 2000 & 1000 & 2000 \mathrm{mg} \text { daily } \\ \text { number } & 129 & 136 & 141 & 138 & 147 & 152\end{array}$

Figure 4 Changes in $\mathrm{HbA}_{I \mathrm{c}}$, fasting and $2 \mathrm{~h}$ prandial glucose and insulin secretion (as determined by 2 hr AUC insulin divided by AUC ${ }_{\text {glucose }}$ after a meal tolerance test) after 24 weeks treatment of sitagliptin and/or metformin, as indicated in bottom. Results reported are adjusted for changes after treatment with placebo. Fig. is drawn after results reported in Goldstein et al 2007. 
$(0.6-1.3 \mathrm{~kg})$ except in the group given sitagliptin alone as monotherapy.

\section{Mechanisms of improved antidiabetic action by combining DPP-4 inhibitors with metformin}

DPP-4 inhibitors have been shown to increase GLP-1 levels both under fasting conditions and following meal ingestion (Ahrén et al 2004b; Mari et al 2005). Furthermore, DPP-4 inhibition improves islet function by stimulating insulin secretion, by improving the glucose sensitivity of the beta cells, and by inhibiting glucagon secretion from the alpha cells (Balas et al 2007; Dunning et al 2005). This reduces both fasting and prandial glucose which reduces $\mathrm{HbA}_{1 \mathrm{c}}$ levels. In contrast to GLP-1, DPP-4 inhibition does not seem to inhibit gastric emptying (Vella et al 2007) and it does not reduce body weight (Ahrén et al 2004b; Aschner et al 2006; Pratley et al 2006; Raz et al 2006; Ristic et al 2005; Rosenstock et al 2007; Schweizer et al 2007; Scott et al 2007). Metformin, on the other hand, reduces hepatic glucose production and improves insulin sensitivity in muscle and liver cells, which improve overall insulin action and reduce mainly fasting glucose (Bailey and Turner 1996; Consoli et al 2994; Donnelly et al 2006; Hundal and Inzucchi 2003; Leverve et al 2003; Stumvoll et al 1995). The efficient improved glycemic control by combing DPP-4 inhibitors with metformin would rely on the complementary mechanism of the two treatments. It has therefore been of interest to mechanistically examine the combination of DPP-4 inhibition and metformin.

\section{GLP-I levels}

One study has examined the effect of the combination of sitagliptin and metformin on concentrations of active and inactive GLP-1 after meal ingestion following 24 weeks of treatment (Migoya et al 2007). It was found that both sitagliptin and metformin alone increased the postmeal concentration of active GLP-1. Furthermore, when given in combination, the increase in active GLP-1 was more than additive, suggesting a synergistic action of the two compounds.

\section{Islet effects when DPP-4 inhibition is added to metformin}

In the initial study on the add-on of vildagliptin to metformin treatment, in which vildagliptin and metformin in combination was compared with metformin alone for 52 weeks (Ahrén et al 2004a), a standardized breakfast meal comprising of $465 \mathrm{kcal}$ was served at baseline and after 12 , 24 and 52 weeks of treatment. The study evaluated insulin secretion by calculating the suprabasal $30 \mathrm{~min}$ area under the C-peptide curve divided by the $30 \mathrm{~min}$ increase in glucose after meal ingestion (Ahrén et al 2005). It was found that glucose tolerance was improved by the combination therapy versus metformin alone. Thus, the mean between-group difference in $\mathrm{AUC}_{\text {glucose }}$ was $256 \mathrm{mmol} / 240 \mathrm{~min}$ compared to a baseline of $545 \mathrm{mmol} / 240 \mathrm{~min}$. Furthermore, insulin secretion increased gradually during the first 24 weeks by the combination therapy and thereafter remained stable for the remaining period of the study (Figure 5). This shows that the combination of vildagliptin with metformin improves beta cell function. The same study also evaluated insulin sensitivity after meal ingestion by calculating the OGIS index (oral glucose insulin sensitivity index). This is a validated index which is based on a model of glucose clearance in relation to meal-derived insulin data (Mari et al 2001). It was found that OGIS gradually increased by the combination therapy (Figure 5). The combined estimation of insulin secretion and insulin sensitivity allowed the estimation of the adaptation index (the product of insulin secretion and sensitivity); the adaptation index gives a figure of the ability of the beta-cell to adapt insulin secretion to the ambient insulin sensitivity (Ahrén and Pacini 1997). It was found (see also Figure 5) that the adaptation index increased by the combination of vildagliptin and metformin versus metformin alone. This change in adaptation index across the entire study group showed a negative correlation with the change in $\mathrm{HbA}_{1 \mathrm{c}}(\mathrm{r}=-0.39$, $\mathrm{p}=0.004$ ) (see Figure 5). Hence, this analysis of potential mechanisms of action underlying the improved glycemic control by the combination of vildagliptin and metformin versus metformin alone showed a marked improvement in beta cell function and a slight improvement in insulin sensitivity which together results in improved beta cell adaptation ability to insulin resistance, a measure that correlated to the reduction in $\mathrm{HbA}_{1 \mathrm{c}}$. Furthermore, from this study, also baseline and prandial proinsulin levels have been carefully analyzed, and the results have shown a reduction in proinsulin levels in subjects given vildagliptin and metformin in combination versus metformin alone (Ahrén et al 2007), which further adds to the conclusion that vildagliptin improves beta cell function when added to metformin in subjects with type 2 diabetes.

Another study has examined glucose tolerance and indirect markers of beta cell function after meal ingestion following 24 weeks of addition of vildagliptin at 50 or $100 \mathrm{mg}$ daily 

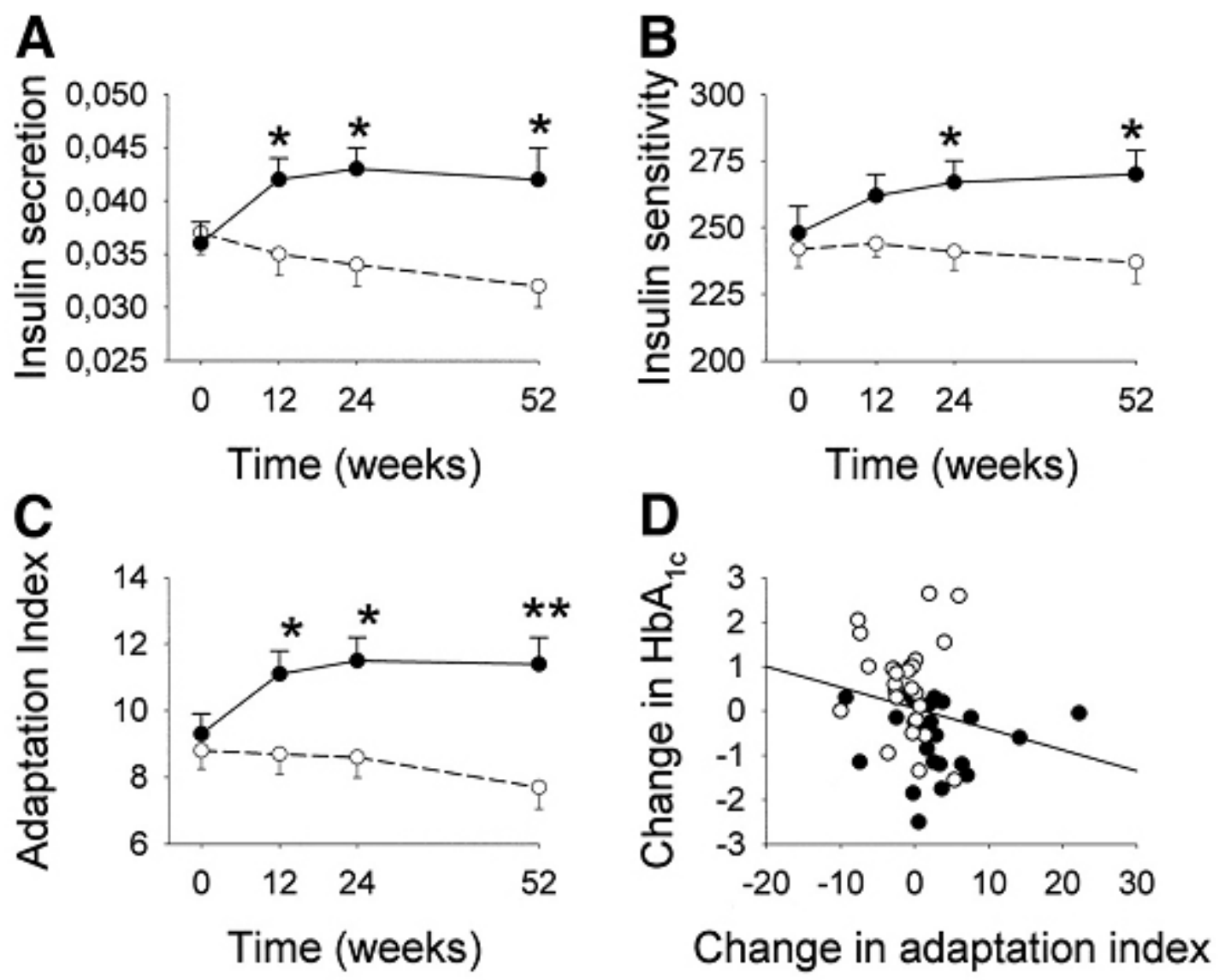

\section{$--\infty-$ Placebo/metformin \\ $\longrightarrow$ Villdagliptin/metformin}

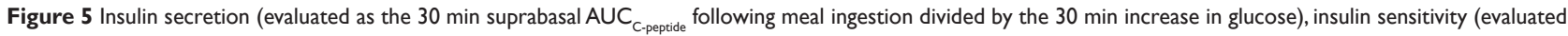
by the OGIS estimation) and adaptation index (insulin secretion times insulin sensitivity) at baseline and after I2, 24 and 52 weeks of treatment with vildagliptin at 50 mg daily in combination with metformin $(n=3 I)$ versus treatment with metformin alone $(n=26)$. Low right panel shows the change in $\mathrm{HbAl}$ c after the 52 week treatment period as a function of change in adaptation index in the same study. Reproduced from Ahrén et al 2005 after permission from the American Diabetes Association.

to on-going metformin ( $>1.5 \mathrm{~g}$ daily) (Bosi et al 2007). A standard breakfast consisting of $500 \mathrm{kcal}$ was served after the 24 week treatment. Glucose tolerance was determined by prandial glucose levels. Insulin secretion was evaluated by calculating the total $2 \mathrm{~h}$ insulin secretion by deconvoluting plasma $\mathrm{C}$-peptide levels and then dividing this figure by the area under the $2 \mathrm{~h}$ glucose curve. It was found that following the 24 weeks of treatment, subjects given vildagliptin (either 50 or $100 \mathrm{mg}$ daily) in combination with metformin had lower fasting and prandial glucose than subjects given metformin alone. For example, the placebo-adjusted mean $2 \mathrm{hr}$ plasma glucose following meal ingestion was reduced by $1.9 \mathrm{mmol} / \mathrm{l}$ by vildagliptin at $50 \mathrm{mg}$ daily and by $2.3 \mathrm{mmol} / 1$ by vildagliptin at $100 \mathrm{mg}$ from a baseline of $13.5 \mathrm{mmol} / \mathrm{l}$. Furthermore, beta cell function, was increased in subjects given vildagliptin in combination with metformin versus metformin alone.
Insulin secretion and insulin sensitivity were also determined in the four week study when sitagliptin at $50 \mathrm{mg}$ twice daily was given to on-going metformin therapy (Brazg et al 2007). Insulin secretion was evaluated by modeling Cpeptide data after a standardized breakfast meal comprising $765 \mathrm{kcal}$ (Breda and Copbelli 2001) and insulin sensitivity was determined with a composite index, insulin sensitivity index (Matsuda and DeFronzo 1999). It was found that insulin secretion, as evaluated by this model, was significantly improved after treatment with sitagliptin in combination with metformin versus with metformin alone (Brazg et al 2007). Furthermore, insulin sensitivity was numerically increased, although this did not reach significance. Finally, the authors also calculated the disposition index, which is insulin secretion (based on insulin levels) times insulin sensitivity, and it was substantially elevated by the combination therapy. Therefore, also this study showed a clear stimulation of 
insulin secretion by the combination of metformin with a DPP-4 inhibitor.

Beta cell function and insulin sensitivity were as well estimated in the 24 week study with sitagliptin at $100 \mathrm{mg}$ once daily as add-on to metformin (Charbonnel et al 2006). It was found that after 24 weeks of treatment, along with a reduction in $\mathrm{HbA}_{1 \mathrm{c}}$ and fasting glucose, the combination of sitagliptin and metformin increased fasting insulin and glucose as well as the homeostasis model assessment of $\beta$-cell function (HOMA- $\beta$, Matthews et al 1985) and the insulin sensitivity marker, quantitative insulin sensitivity check (QUICKI, Katz et al 2000). Furthermore, the combination of sitagliptin and metformin also reduced the proinsulin to insulin ratio under fasting conditions, which is a sign of improved beta cell function. In contrast, in this study, fasting proinsulin levels per se were not altered and the homeostasis model assessment of insulin resistance (HOMA-IR), which is based on the fasting levels of glucose and insulin (Matthews et al 1985) was not altered. Furthermore, in this study, the subjects also received a standardized meal after 24 weeks treatment. It was found that sitagliptin in combination with metformin significantly reduced the post-meal glycemia in association with enhancement of postmeal insulin and C-peptide levels as well as the determination of insulin secretion by calculating the postmeal insulin to glucose ratio, all in comparison with treatment with metformin alone.

\section{Islet function when DPP-4 inhibition and metformin are used in initial combination therapy}

In the study in which sitagliptin and metformin are given as initial combination therapy (Goldstein et al 2007), a standardized meal tolerance test was given after 24 weeks of treatment with analyses of glucose, insulin and C-peptide. It was found that along with the reduction in fasting glucose, the prandial glycemia was improved both by sitagliptin and metformin in monotherapy but an additive effect in reducing prandial glycemia was observed. Thus, the placebo-adjusted reduction in mean $2 \mathrm{~h}$ postmeal glucose was $6.5 \mathrm{mmol} / \mathrm{from}$ the baseline $2 \mathrm{hr}$ glucose of $15.9 \mathrm{mmol} / \mathrm{l}$ in the subjects given sitagliptin $50 \mathrm{mg}+$ metformin $1000 \mathrm{mg}$ twice daily. Also insulin secretion, as determined by the $\mathrm{AUC}_{\text {insulin }}$ divided by $\mathrm{AUC}_{\text {glucose }}$ during the $2 \mathrm{hr}$ postmeal period, was significantly increased by the combination therapy in an additive manner versus monotherapy. Thus, the placebo-adjusted increase in mean insulin secretion was $0.07 \mu \mathrm{U} \mathrm{hr}$ insulin $/ \mathrm{ml} / \mathrm{mg}$ h glucose $/ \mathrm{dl}$ versus 0.16 at baseline, ie, an increase by $43 \%$. The study also showed a significant reduction in fasting proinsulin and in fasting proinsulin to insulin ratios after 24 weeks treatment with the combination of sitagliptin and metformin, again reinforcing an improved beta-cell function by this combination therapy. Furthermore, when calculating the insulin resistance index, HOMA-IR, a marked improvement in insulin sensitivity was seen by the combination; the placebo-adjusted value of HOMAIR was reduced by 2.7 from a baseline of 6.2 , ie, by $41 \%$.

To summarize, the mechanistic studies of combination treatment with DPP-4 inhibition and metformin show increased GLP-1 levels and increased insulin secretion and insulin sensitivity. Nevertheless, more studies are required to fully understand the benefits of this combination, including effects on glucagon secretion.

\section{Conclusions}

DPP-4 inhibition has been shown to be antidiabetic when used both in monotherapy (Ahrén et al 2004b; Aschner et al 2006; Pratley et al 2006; Raz et al 2006; Ristic et al 2005; Rosenstock et al 2007; Schweizer et al 2007; Scott et al 2007) and in combination with metformin (Ahrén et al 2004a; Bosi et al 2007; Brazg et al 2007; Charbonnel et al 2006; Goldstein et al 2007), thiazolidinediones (Garber et al 2007; Rosenstock et al 2006; Rosenstock et al 2007) and insulin (Fonseca et al 2007). This novel strategy to treat type 2 diabetes is expected to be of increasing value in the future treatment of type 2 diabetes. The overall experience is that this novel strategy is efficient, highly tolerable and safe with a minimal risk for hypoglycemic events. A promising place in therapy for DPP-4 inhibition is in combination with metformin. This has been demonstrated in large studies with vildagliptin and sitagliptin, since these studies have shown that $\mathrm{HbA}_{1 \mathrm{c}}$ is reduced by $0.65 \%-1.1 \%$ from baseline levels of $7.8 \%-8.4 \%$ in studies up to 52 weeks. This improvement in glycemic control is similar as in studies with sulphonylureas, thizolidinediones or exenatide when added to metformin treatment. Furthermore, DPP-4 inhibition in combination with metformin is safe and tolerable. Hence, a major indication for treatment with DPP-4 inhibition as add-on to metformin in subjects inadequately controlled with metformin and as first-line treatment in initial combination therapy with metformin. For future studies, the durability of effects of the combination of DPP-4 inhibition with metformin needs to be explored as well as more detailed mechanistic studies need to be undertaken, with particular to studies on glucagon secretion, prandial lipid levels and insulin sensitivity. 


\section{References}

Ahrén B. 2006. Vildagliptin: an inhibitor of dipeptidyl peptidase-4 with antidiabetic properties. Exp Opin Invest Drugs, 15:431-42.

Ahrén B. 2007a. Dipeptidyl peptidase-4 inhibitors - clinical data and clinical implications. Diabetes Care, 30:1344-50.

Ahrén B. 2007b. DPP-4 inhibitors. In: A Barnett, C Bailey eds. Best practice and research: clinical endocrinology and metabolism; novel therapies of diabetes. In press.

Ahrén B, Pacini G. 1997. Impaired adaptation of first-phase insulin secretion in postmenopausal women with glucose tolerance. Am J Physiol, 273:E701-7.

Ahrén B, Simonsson E, Larsson H, et al. 2002. Inhibition of dipeptidyl peptidase IV improves metabolic control over a 4 week study period in type 2 diabetes. Diabetes Care, 25:869-75.

Ahrén B, Schmitz O. 2004. GLP-1 receptor agonists and DPP-4 inhibitors in the treatment of type 2 diabetes. Horm Metab Res, 36:867-76.

Ahrén B, Gomis R, Standl E, et al. 2004a. Twelve- and 52-week efficacy of the dipeptidyl peptidase IV inhibitor LAF237 in metformin-treated patients with type 2 diabetes. Diabetes Care, 27:2874-80.

Ahrén B, Landin-Olsson M, Jansson PA. 2004b. Inhibition of dipeptidyl peptidase-4 reduces glycemia, sustains insulin levels and reduces glucagon levels in type 2 diabetes. J Clin Endocrinol Metab, 89:2078-84.

Ahrén B, Foley JE, Pacini G, et al. 2005. Improved meal-related $\beta$-cell function and insulin sensitivity by the dipeptidyl peptidase-IV inhibitor vildagliptin in metformin-treated patients with type 2 diabetes over 1 year. Diabetes Care, 28:1936-40.

Ahrén B, Pacini G, Tura A, et al. 2007. Improved meal-related insulin processing contributes to the enhancement of B-cell function by the DPP-4 inhibitor vildagliptin in patients with type 2 diabetes. Horm Metab Res, 39:826-9.

Aschner P, Kipnes MS, Lunceford JK, et al. 2006 Effect of the dipeptidyl peptidase-4 inhibitor sitagliptin as monotherapy on glycemic control in patients with type 2 diabetes. Diabetes Care, 29:2632-7.

Bailey CJ, Turner RC. 1996. Metformin. N Engl J Med, 334:574-9.

Balas B, Baig MR, Watson C, et al. 2007. The dipeptidyl peptidase IV inhibitor vildagliptin suppresses endogenous glucose production and enhances islet function after single-dose administration in type 2 diabetic patients. J Clin Endocrinol Metab, 92:1249-55.

Bosi E, Camisasca RP, Collober C, et al. 2007. Effects of vlidagliptin on glucose control over 24 weeks in patients with type 2 diabetes inadequately controlled with metformin. Diabetes Care, 30:890-5.

Brazg R, Xu L, Dalla Man C, et al. 2007. Effect of adding sitagliptin, a dipeptidyl peptidase-4 inhibitor, to metformin on 24-h glycaemic control and $\beta$-cell function in patients with type 2 diabetes. Diabetes Obes Metab, 9:186-93.

Breda E, Cobelli C. 2001. Insulin secretion rate during glucose stimuli: alternative analyses of C-peptide data. Ann Biomed Eng, 29:692-700.

Charbonnel B, Schernthaner G, Brunetti P, et al. 2005. Long-term efficacy and tolerability of add-on pioglitazone therapy to failing monotherapy compared with addition of gliclazide or metformin in patients with type 2 diabetes. Diabetes, 48:1093-104.

Charbonnel B, Wu M, Karasik A, et al. 2006. Efficacy and safety of the dipeptidyl peptidase-4 inhibitor sitagliptin added to ongoing metformin therapy in patients with type 2 diabetes inadequately controlled with metformin alone. Diabetes Care, 29:2638-43.

Consoli A, Gomis R, Halimi S, et al. 2004. Initiating oral glucose-lowering therapy with metformin in type 2 diabetic patients: an evidence-based strategy to reduce the burden of late-developing diabetes complications. Diabetes Metab, 30:509-16.

Deacon CF. 2007. Dipeptidyl peptidase 4 inhibition with sitagliptin: a new therapy for type 2 diabetes. Exp Opin Invest Drugs, 16:533-45.

DeFronzo R, Hissa M, Blauwet MB, et al. 2007. Saxagliptin added to metformin improves glycemic control in patients with type 2 diabetes. Diabetes, 56(Suppl 1):A74.

DeFronzo RA. 2004. Pathogenesis of type 2 diabetes mellitus. Med Clin North Am, 88:787-835.
DeFronzo RA, Ratner RE, Han J, et al. 2005. Effects of exenatide (exendin4) on glycemic control and weight over 30 weeks in metformin-treated patients with type 2 diabetes. Diabetes Care, 28:1092-100.

Del Prato S, Pulizzi N. 2006. The place of sulfonylureas in the therapy for type 2 diabetes mellitus. Metabolism, 55:S20-7.

Derosa S, Gaddi AV, Piccinni MN, et al. 2006. Differential effect of glimepiride and rosiglitazone on metabolic control of type 2 diabetic patients treated with metformin: a randomized double-blind, clinical trial. Diabetes Obes Metab, 8:197-205.

Donnelly LA, Foney ASF, Hattersley AT, et al. 2006. The effect of obesity on glycaemic response to metformin or sulphonylureas in type 2 diabetes. Diabetic Med, 23:128-33.

Drucker DJ, Nauck MA. 2006. The incretin system: glucagon-like peptide-1 receptor agonists and dipeptidyl peptidase- 4 inhibitors in type 2 diabetes. Lancet, 368:1696-705.

Dunning BE, Foley J, Ahrén B. 2005. Alpha-cell function in health and disease: influence of GLP-1. Diabetologia, 48:1700-13.

Fenglos MM, Saad MF, Pi-Sinyer FX, et al. 2005. Effects of liragflutide (NN2211), a long-acting GLP-1 analogue, on glycaemic control and bodyweight in subjects with type 2 diabetes. Diabet Med, 22:1016-23.

Fonseca V, Schweizer A, Albrecht D, et al. 2007. Addition of vildagliptin to insulin improves glycaemic control in type 2 diabetes. Diabetologia, 50:1148-55.

Gallwitz B. 2007. Review of sitagliptin phosphate: a novel treatment for type 2 diabetes. Vasc Health Risk Manag, 3:203-10.

Garber AJ, Schweizer A, Baron MA, et al. 2007. Vildagliptin in combination with pioglitazone improves glycaemic control in patients with type 2 diabetes failing thiazolidinedione monotherapy: a randomized, placebo-controlled study. Diabet Obes Metab, 9:166-74.

Ginnarelli R, Aragona M, Coppelli A, et al. 2003. Reducing insulin resistance with metformin: the evidence today. Diabetes Metab, 29:6S28-35.

Goldstein BJ, Feinglos MN, Lunceford JK, et al. 2007. Effect of initial combination therapy with sitagliptin, a dipeptidyl peptidase-4 inhibitor, and metformin on glycemic control in patients with type 2 diabetes. Diabetes Care, 30:1979-87.

Green JB, Feinglos MN. 2007. Are sulphonylureas passé? Curr Diabet Rep, 6:373-7.

Gutzwiller JP, Drewe J, Göke B, et al. 1999. Glucagon-like peptide-1 promotes satiety and reduces food intake in patients with diabetes mellitus type 2. Am J Physiol, 276:R1541-4.

Herman GA, Bergman A, Yi B, et al. 2006. Tolerability and pharmacokinetics of metformin and the dipeptidyl peptidase 4 inhibitor sitagliptin when co-administered in patients with type 2 diabetes. Curr Med Res Opin, 22:1939-47.

Hinke SA, Kuhn-Wache K, Hoffman T, et al. 2002. Metformin effects on dipeptidylpeptidase IV degradation of glucagon-like peptide-1. Biochem Biophys Res Commun, 291:1302-8.

Holst JJ, Deacon CF. 1998. Inhibition of the activity of dipeptidyl-peptidase IV as a treatment for type 2 diabetes. Diabetes, 47:1663-70.

Hundal RS, Inzucchi SE. 2003. Metformin: new understandings, new uses. Drugs, 63:1879-94.

Ikeda T, Iwata K, Murakami H. 2000. Inhibitory effect of metformin on intestinal glucose absorption in the perfused rat intestine. Biochem Biopharmacol, 59:887-90.

Inzucchi SE. 2002. Oral antihyperglycemic therapy for type 2 diabetes: scientific review. JAMA, 287:360-72.

Kahn SE. 2001. The importance of beta-cell failure in the development and progression of type 2 diabetes. J Clin Endocrinol Metab, 86:4047-58.

Kahn SE, Haffner, SM, Helse MA, et al. 2006. Glycemic durability of rosiglitazone, metformin, or glyburide monotherapy. $N$ Engl J Med, 355:2427-43.

Karasik A, Wu M, Williams-Herman D, et al. 2007. Sitagliptin added to ongoing metformin therapy provides sustained glycemic control over 54 weeks, with a low incidence of hypoglycaemia and with weight loss. Diabetes, 56(Suppl 1):A139. 
Katz A, Nambi SS, Mather K, et al. 2007. Quantitative insulin sensitivity check index: a simple, accurate method for assessing insulin sensitivity in humans. J Clin Endocrinol Metab, 85:2402-10.

Kim D, Wang L, Beconi M, et al. 2005. (2R)-4-oxo-4-[3-(trifluoromethyl)5,6-dihydro[1,2,4]triazol[4,3,a]pyrazin-7(8H)-yl]-1-(2,4,5-trifluorophenyl)butan-2-amine: a potent, orally active dipeptidyl peptidase IV inhibitor for the treatment of type 2 diabetes. J Med Chem, 48:141-51.

Leverve KM, Guigas B, Detaille D, et al. 2003. Mitochondrial metabolism and type-2 diabetes: a specific target of metformin. Diabetes Metab, 29:6S88-94.

Levetran C. 2007. Oral antidiabeti agents in type 2 diabetes. Curr Med Res Opin, 23:945-52.

Lindsay JR, Duffy NA, McKillop AM, et al. 2005. Inhibition of dipeptidyl peptidase IV activity by oral metformin in type 2 diabetes. Diabet Med, 22:654-7.

Mannucci E, Pierazzuoli E, Ognibene A, et al. 2001. Effect of metformin on glucagon-like peptide 1 (GLP-1) and leptin levels in obese nondiabetic subjects. Diabetes Care, 24:489-94.

Mari A, Pacini G, Murphy E, et al. 2001. A model-based method for assessing insulin sensitivity from the oral glucose tolerance test. Diabetes Care, 24:539-48

Mari A, Sallas WM, He YL, et al. 2005. Vildagliptin, a dipeptidyl peptidaseIV inhibitor, improves model-assessed beta-cell function in patients with type 2 diabetes. J Clin Endocrinol Metab, 90:4888-94.

Matsuda M, DeFronzo RA. 1999. Insulin sensitivity indices obtained from oral glucose tolerance testing: comparison with the euglycemic insulin clamp. Diabetes Care, 22:1462-70.

Matthews DR, Hosker JP, Rudenski AS, et al. 1985. Homeostasis model assessment: insulin resistance and beta cell function from fasting plasma glucose and insulin concentrations in man. Diabetologia, 28:412-19.

Mentlein R. 1999. Dipeptidyl-peptidase IV (CD26) - role in the inactivation of regulatory peptides. Regul Pept, 85:9-24.

Migoya EM, Miller J, Larson P, et al. 2007. Sitagliptin, a selective DPP-4 inhibitor, and metformin have complementary effects to increase active GLP-1 concentrations. Diabetes, 56(Suppl 1):A74.

Nathan DM, Buse JB, Davidson MB, et al. 2006. Management of hyperglycemia in type 2 diabetes: a consensus algorithm for the initiation and adjustment of therapy. A consensus statement from the American Diabetes Association and the European Association for the Study of Diabetes. Diabetes Care, 29:1963-72.

Nauck MA, Niedereichholz U, Ettler R, et al. 1997. Glucagon-like peptide-1 inhibition of gastric emptying outweighs its insulinotropic effects in healthy humans. Am J Physiol, 36:E981-8.

Nauck MA, Meininger G, Sheng D, et al. 2007. Efficacy and safety of the dipeptidyl peptidase-4 inhibitor, sitagliptin, compared with the sulfonylurea, glipizide, in patients with type 2 diabetes inadequately controlled on metformin alone: a randomized double-blind, non-inferiority trial. Diabet Obes Metab, 9:194-205.

Nissen SE, Wolski K. 2007. Effect of rosiglitazoine on the risk of myocardial infarction and death from cardiovascular causes. $N$ Engl $\mathrm{J} \mathrm{Med}$, $356: 2457-71$.
Perfetti R, Hui H. 2004. The role of GLP-1 in the life and death of pancreatic beta cells. Horm Metab Res, 36:804-10.

Pratley RE, Jauffret-Kamel S, et al. 2006. Twelve-week monotherapy with the DPP-4 inhibitor vildagliptin improves glycemic control in subjects with type 2 diabetes. Horm Metab Res, 387:423-38.

Raz I, Hanefeld M, Xu L, et al. 2006. Efficacy and safety of the dipeptidyl peptidase-4 inhibitor sitagliptin as monotherapy in patients with type 2 diabetes mellitus. Diabetologia, 49:2564-71.

Ristic S, Byiers S, Foley J, et al. 2005. Improved glycaemic control with dipeptidyl peptidase-4 inhibition in patients with type 2 diabetes: vildagliptin (LAF237) dose response. Diabet Obes Metab, 7:692-8.

Rosenstock J, Brazg R, Andryuk PJ, et al. 2006 Efficacy and safety of the dipeptidyl peptidase-4 inhibitor sitagliptin added to ongoing pioglitazone therapy in patients with type 2 diabetes: a 24 -week multicenter, randomized, double-blind, placebo-controlled, parallel-group study. Clin Ther, 28:1556-68.

.Rosenstock J, Baron MA, Camisasca RP, et al. 2007. Efficacy and tolerability of initial combination therapy with vildagliptin and pioglitazone compared with component monotherapy in patients with type 2 diabetes. Diabetes Obes Metab, 9:175-85.

Schweizer A, Couturier A, Foley JE, et al. 2007. Comparison between vildagliptin and metformin to sustain reductions in $\mathrm{HbA}_{1 \mathrm{c}}$ over 1 year in drug-naïve patients with type 2 diabetes. Diabet Med, 24:955-61.

Scott R, Wu M, Sanchez M, et al. 2007. Efficacy and tolerability of the dipeptidyl peptidase-4 inhibitor sitagliptin as monotherapy over 12 weeks in patients with type 2 diabetes. Int J Clin Pract, 61:171-80.

Setter SM, Iltz JL, Thams J, et al. 2003. Metformin hydrochloride in the treatment of type 2 diabetes mellitus: a clinical review with a focus on dual therapy. Clin Ther, 25:2991-3026.

Stratton IM, Adler AI, Neil HA, et al. 2000. Association of glycaemia with macrovascular and microvascular complications of type 2 diabetes (UKPDS 35): prospective observational study. $\mathrm{Br}$ Med J, 321:405-12.

Stumvoll M, Nurjhan N, Perriello G, et al. 1995. Metabolic effects of metformin in non-insulin-dependent diabetes mellitus. $N$ Engl J Med, 333:550-4.

Umpierrez G, Issa M, Vlanjnic A. 2006. Glimepiride versus pioglitazone combination therapy in subjects with type 2 diabetes inadequately controlled on metformin monotherapy: results of a randomized clinical trial. Curr Med Res Opin, 22:751-9.

Vella A, Bock G, Giesler PD, et al. 2007. Effects of dipeptidyl peptidase 4 inhibition on gastrointestinal function, meal appearance and glucose metabolism in type 2 diabetes. Diabetes, 56:1475-80.

Vilsbøll T, Krarup T, Madsbad S, et al. 2002. Defective amplification of the late phase insulin response to glucose by GIP in obese type II diabetic patients. Diabetologia, 45:1111-19. 